\title{
Antiangiogenic cancer therapy combined with oncolytic virotherapy leads to regression of established tumors in mice
}

\author{
Timothy Kottke, ${ }^{1}$ Geoff Hall,, ${ }^{2}$ Jose Pulido,, ${ }^{1,3}$ Rosa Maria Diaz, ${ }^{1}$ Jill Thompson, ${ }^{1}$ Heung Chong, ${ }^{4}$ \\ Peter Selby, ${ }^{2}$ Matt Coffey, ${ }^{5}$ Hardev Pandha, ${ }^{6}$ John Chester, ${ }^{2}$ Alan Melcher, ${ }^{2}$ \\ Kevin Harrington, ${ }^{7}$ and Richard Vile ${ }^{1,2,8}$
}

\begin{abstract}
1Department of Molecular Medicine, Mayo Clinic, Rochester, Minnesota, USA. Cancer Research UK Clinical Centre, St. James' University Hospital, Leeds, United Kingdom. ${ }^{3}$ Department of Ophthalmology and Ocular Oncology, ${ }^{4}$ St George's Hospital Medical School, Tooting, London, United Kingdom. ${ }^{5}$ Oncolytics Biotech Inc., Calgary, Canada. ${ }^{6}$ Department of Oncology, University of Surrey, Guildford, United Kingdom.

${ }^{7}$ The Institute of Cancer Research, London, United Kingdom. ${ }^{8}$ Department of Immunology, Mayo Clinic, Rochester, Minnesota, USA.
\end{abstract}

\begin{abstract}
Clinical trials of oncolytic virotherapy have shown low toxicity and encouraging signs of efficacy. However, it remains critically important to develop methods for systemic viral delivery if such therapies are to be clinically implemented to treat established tumors. In this respect, much effort is being focused on combining oncolytic viruses with standard treatment modalities such as inhibitors of $\mathrm{VEGF}_{165}$ (an alternatively spliced isoform of VEGF-A) signaling, which are widely used to treat several different cancers. Here, we have demonstrated that combining VEGF 165 inhibitors with systemic delivery of oncolytic viruses leads to substantial regression and cure of established tumors in immunocompetent mice. We have shown that manipulating $\mathrm{VEGF}_{165}$-mediated $^{-}$ signaling by administering $V_{E G F}$ to mice harboring mouse melanoma cells that do not express $V_{E G F}$ and by administering a VEGF inhibitor and then withdrawing treatment to allow VEGF levels to rebound in mice harboring mouse melanoma cells expressing $\mathrm{VEGF}_{165}$ allows tumor-associated endothelial cells transiently to support viral replication. This approach led to direct tumor cell lysis and triggered innate immune-mediated attack on the tumor vasculature. It also resulted in long-term antitumor effects, even against tumors in which viral replication is poorly supported. Since this combinatorial approach targets the tumor endothelium, we believe these data have direct, wide-ranging, and immediate clinical applicability across a broad range of tumor types.
\end{abstract}

\section{Introduction}

Cancer gene/virus therapy will not achieve its potential until vectors can be delivered systemically to metastatic disease (1). Many barriers exist in immunocompetent hosts, including immune inactivation, mislocalization, specific and nonspecific sequestration, and inadequate intratumoral extravasation $(1,2)$. In virus-immune hosts, neutralizing antibody (NAb) also inhibits intratumoral delivery, although it can protect against widespread viral dissemination/toxicity (3). Transient immunosuppression can modulate NAb and other immune effectors to enhance viral delivery $(3,4)$. We (5-7) and others $(8,9)$ have also used cells to protect viruses from circulating immune elements and to chaperone them into tumors (2).

Vectors directly injected into human tumors fail to migrate beyond the needle track (10). Thus, replication-competent vectors have been developed that, theoretically, can initiate comprehensive, spreading intratumoral infections from low-level initial seeding $(11,12)$. A portfolio of oncolytic viruses with replicative selectivity for tumor cells is being tested $(13,14)$. Reovirus (Reo) is selectively cytotoxic to Ras-activated tumor cells (15) and has efficacy in immunocompetent and -deficient models (16-20). We conducted phase I clinical trials with systemically delivered Reo (21-23). Interestingly, these and other studies have shown systemic virus delivery to tumors, despite high NAb titers (21-24). Nonetheless, significant problems

Authorship note: Kevin Harrington and Richard Vile are co-senior authors. Conflict of interest: The authors have declared that no conflict of interest exists. Citation for this article: J Clin Invest. 2010;120(5):1551-1560. doi:10.1172/JCI41431. persist in achieving efficient systemic viral delivery, and much effort is now focusing on combining oncolytic viruses with standard treatment modalities $(25,26)$.

Tumor vasculature represents both a target for and a barrier to systemic virotherapy (27-30). Many human tumors overexpress VEGF, particularly VEGF 165 (an alternatively spliced isoform of VEGF-A), to support their own growth $(27,31,32)$. VEGF 165 binds to vasculatureassociated VEGFR2 and mediates tumor angiogenesis (33). The biological importance of this process is underscored by the development of clinically approved VEGF-targeting therapeutics (Avastin/bevacizumab, sorafenib, sunitinib) (34-37). VEGF has multiple effects on tumor vasculature, increasing vasodilation, permeabilization, and disorganization (27,32). Indeed, VEGF was initially called vascular permeability factor (31). Anti-VEGF therapies may "normalize" tumor vasculature, an effect that may improve tumor blood flow and increase delivery of therapies (38). In murine tumor models, the window of vessel normalization is short (days following treatment) $(27,38)$.

We initially hypothesized that transient destabilization of tumor vasculature by VEGF $_{165}$ may facilitate intratumoral delivery of oncolytic viruses. Although administration of a proangiogenic factor to cancer patients seems counterintuitive, we aimed to identify dose schedules that transiently destabilize vasculature, thereby enhancing virus delivery, without promoting long-term tumor growth. Using non-VEGF-expressing tumors in immunocompetent mice, we achieved long-term cures in mice treated with $V_{E G F} F_{165}$ followed, after a specific interval, by i.v. Reo. Although VEGF $_{165}$ enhanced vascular leakage, therapeutic effects derived mainly from $V_{E G F} F_{165}$-mediated stimulation of endothelial cells transiently to support viral replica- 

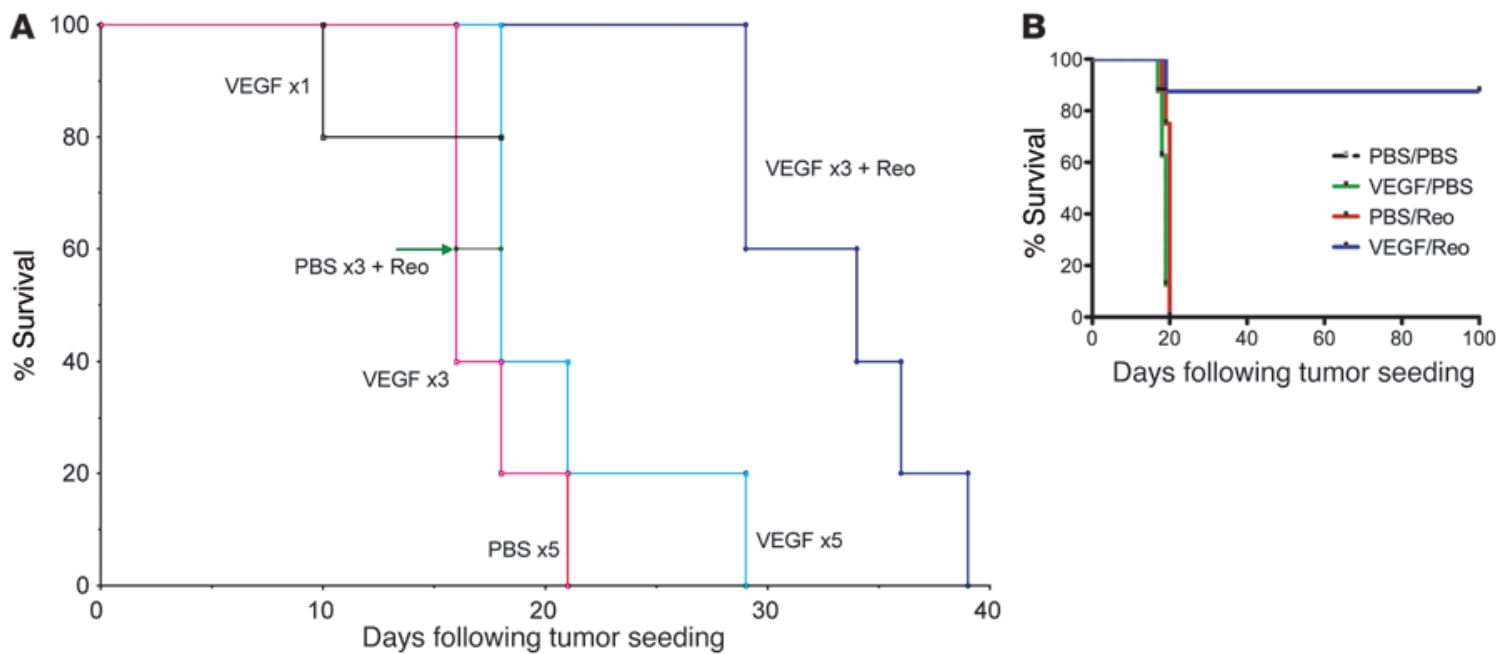

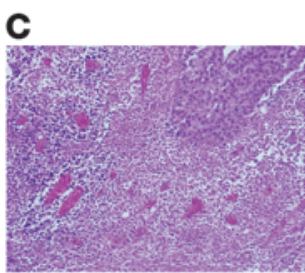

VEGF + Reo iv

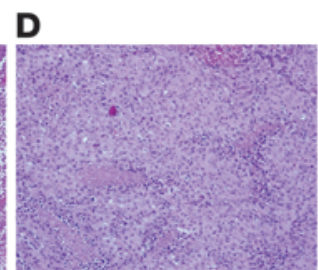

PBS + Reo iv

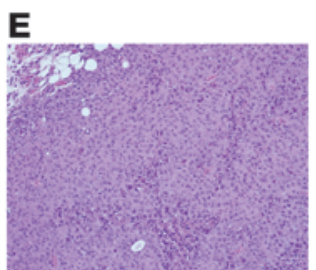

PBS/Reo
$\mathbf{F}$

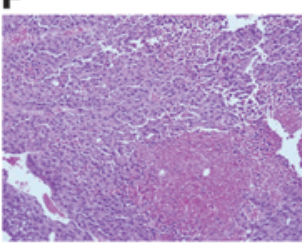

VEGF/Reo

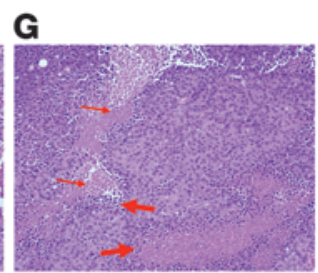

VEGF/Reo

\section{Figure 1}

VEGF $_{165}$ conditions tumors for systemic Reo therapy. (A) Mice bearing B16 tumors established subcutaneously 7 days previously in C57BL/6 mice (5/group) were treated with a single injection per day for 1,3 , or 5 consecutive days of VEGF $165(1 \mu \mathrm{g} / \mathrm{injection})(\mathrm{VEGF} \times 1, \times 3$, or $\times 5)$; 5 daily injections of PBS $(\mathrm{PBS} \times 5)$; 3 daily injections of PBS followed 24 hours later by a single i.v. injection of Reo $\left(5 \times 10^{8} \mathrm{TCID}_{50}\right)$ (PBS $\times 3+$ Reo); or 3 daily injections of VEGF $_{165}$ followed 24 hours later by a single i.v. injection of Reo $($ VEGF $\times 3+$ Reo). Survival (tumor reaching $1.0 \mathrm{~cm}$ in diameter) was followed over time. (B) C57BL/6 mice bearing B16 tumors established 7 days previously in C57BL/6 mice (7-8/group) were treated (days 1-3) with a single injection per day for 3 consecutive days of VEGF 165 or PBS, followed 24 hours later (days $4,5)$ by a single i.v. injection per day for 2 consecutive days of Reo or PBS. This regimen was then repeated (days 8-12 and 15-19) twice in surviving mice. Survival (tumor reaching $1.0 \mathrm{~cm}$ in diameter) was followed over time. (C and D) Subcutaneous B16 tumors were examined histologically after being excised 24 hours following a single i.v. injection of Reo administered 24 hours after a single injection per day for 3 consecutive days of either (C) VEGF 165 or (D) PBS. (E-G) Subcutaneous B16 tumors were examined histologically after being excised 72 hours following 2 daily i.v. injections of Reo administered 24 hours after a single injection per day for 3 consecutive days of either (E) PBS or (F and $\mathbf{G})$ VEGF 165 . Intratumoral hemorrhage/necrosis is shown in $\mathbf{F}$. Perivascular immune infiltrates (thick red arrow) and indistinct tortuous blood vessels (thin red arrow) are shown in G. Original magnification, $\times 20$.

tion. Appropriately timed systemic virus delivery led to replication in and lysis of tumor-associated endothelial cells and innate immunemediated antivascular effects with subsequent vascular collapse. By extending this principle to tumors overexpressing $V_{E G F}$ 165, we combined clinically approved VEGF $_{165}$ inhibitors with virus delivery to achieve long-term cures. Therefore, we have developed here what we believe is a novel method by which clinically approved inhibitors of VEGF $_{165}$ can be combined with systemic delivery of oncolytic viruses to treat established tumors. Since this approach targets the tumor endothelium rather than any specific tumor type, these data support immediate clinical testing of combinations of oncolytic virotherapy and agents that modulate VEGF signaling to tumor vasculature across a potentially broad range of cancers.

\section{Results}

Systemic VEGF ${ }_{165}$ conditions tumors for virotherapy. Up to 5 daily doses $(1 \mu \mathrm{g})$ of $\mathrm{VEGF}_{165}$ did not promote growth of $\mathrm{VEGF}_{165}$-nonproducing B16 tumors (Figure $1 \mathrm{~A})$ ). At least 3 daily VEGF ${ }_{165}$ injections were required to induce vascular leakage as determined by wet/dry lung weight ratios (data not shown) (6). Although i.v. Reo is minimally therapeutic in the B16/C57BL/6 model (Figure 1A), 3 daily $V_{E G F}$ ins injections followed by 1 i.v. Reo injection was therapeutic ( $P<0.01$ vs. VEGF $_{165}$ or Reo) (Figure $\left.1 \mathrm{~A}\right)$. Two daily $V G_{165}$ injections followed by Reo i.v. was not superior to Reo alone. The effect of $\left(V_{E G F} 165\right) \times 3+$ Reo was not increased with 4 or 5 VEGF $_{165}$ injections (data not shown).

Evaluation of multiple $\mathrm{VEGF}_{165} /$ Reo schedules revealed that a regimen of $V_{E G F} F_{165}$ (days 1, 2, 3) followed 24 hours later by i.v. Reo (days 4,5 ), which was repeated 3 times (days $1-5,8-12$, and 15-19), generated significant antitumor therapy $(P<0.001)$ compared with control regimens $((\operatorname{PBS} \times 3)+($ Reo $\times 2)$ or $\left(\right.$ VEGF $\left._{165} \times 3\right)+($ PBS $\left.\times 2)\right)($ Figure $1 \mathrm{~B})$.

Tumors harvested 24 hours after $\left(\operatorname{VEGF}_{165} \times 3\right)+$ Reo treatment contained necrotic tumor and perivascular lymphocyte infiltrates (Figure 1, C and D). By 72 hours, extensive vasodilation, necrosis, and intratumoral hemorrhage were observed in regressing tumors. Frequently, the integrity of intratumoral vessels could not be determined (Figure 1, E-G). 
A

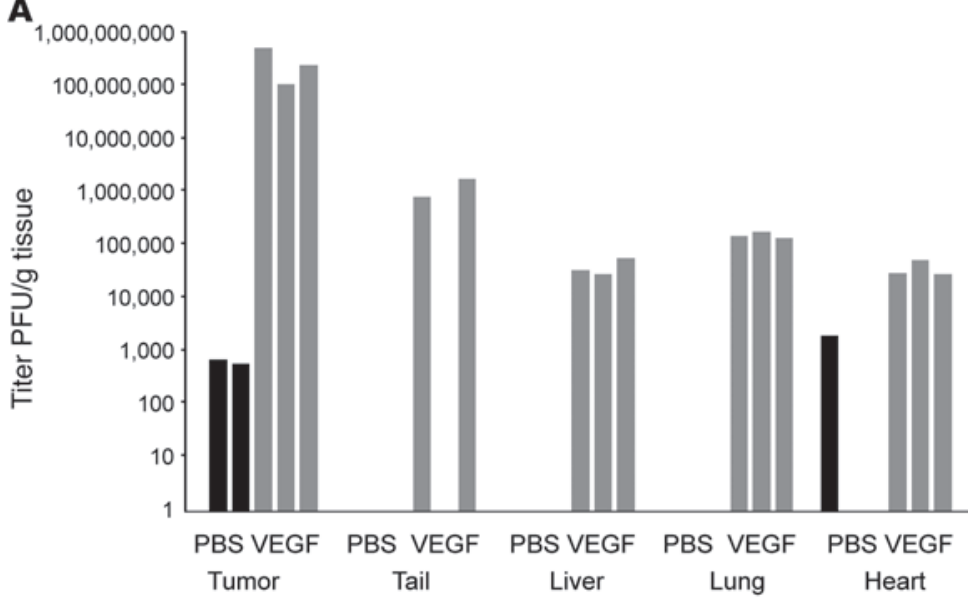

B

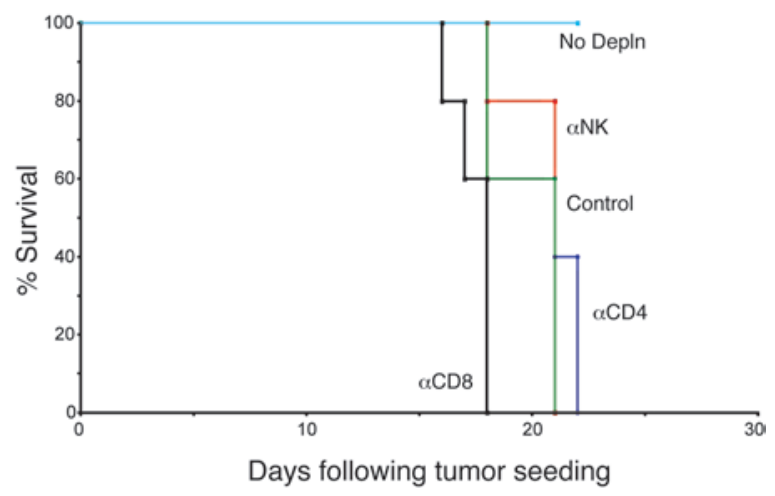

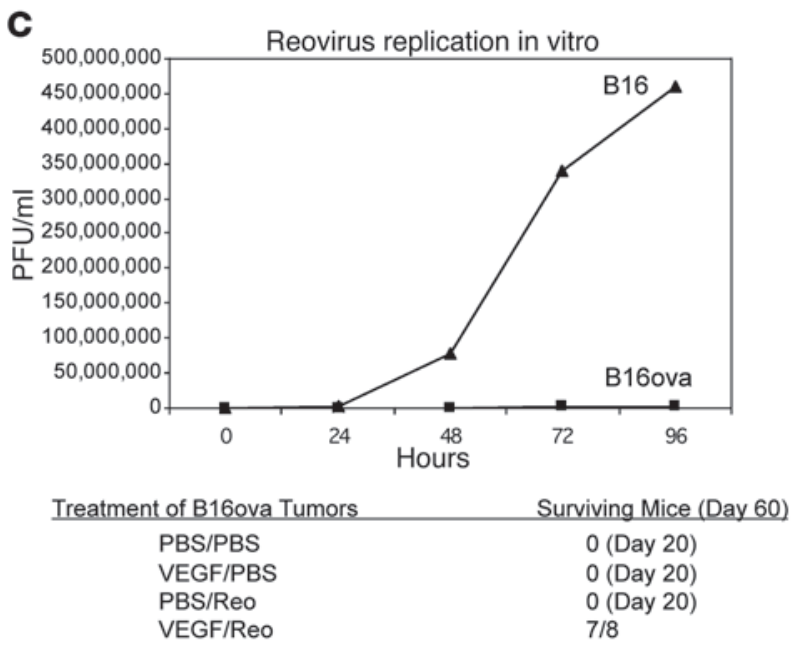

C

\section{Figure 2}

VEGF $_{165}$ sensitization to Reo therapy involves host cells. (A) Viral titers from organs of mice bearing 10-day tumors treated with a single injection per day for 3 consecutive days of VEGF 165 or PBS, followed 24 hours later by a single i.v. injection per day for 2 consecutive days of Reo. (B) Mice bearing 5-day established B16 tumors (5/group) were left intact (2 i.p. injection of IgG, days 6, 7 [No Depln]) or were depleted of CD8 ( $\alpha$-CD8), CD4 $(\alpha-C D 4)$, or NK cells $(\alpha-N K)$. Mice were then treated (days $8-10)$ with VEGF 165 or PBS, followed by Reo or PBS (control) (days 11, 12 ) as in A. (C) Top panel: viral titers recovered from B16ova or B16 cells infected in vitro with Reo (MOI 0.1). Bottom panel: mice bearing 7-day established B16ova tumors were treated with VEGF 165 or PBS (days 1-3), followed by Reo or PBS (days 4, 5) as in A. This regimen was repeated (days 8-12 and 15-19) twice. Mice surviving by day 60 are shown. (D) MyD88-deficient mice bearing 7-day established B16 tumors (7-8/group) were treated with VEGF 165 or PBS (days 1-3) followed by Reo or PBS (days 4, 5) as in A. This regimen was repeated (days 8-12 and 15-19) twice. (E) RT-PCR with primers for endothelial TIE2, tumor-specific gp100, or GAPDH using RNA from B16 tumors 48 hours following 2 i.v. injections of PBS or Reo 24 hours following 3 consecutive daily injections of either VEGF 165 or PBS. **Positive for TIE2 upon nested PCR.

Systemic VEGF 165 enhances virus localization in tumors. One cycle of $\left(\right.$ VEGF $\left._{165} \times 3\right)+($ Reo $\times 2)$ significantly increased systemic reoviral delivery to subcutaneous tumors $(P<0.001$ vs. $($ PBS $\times 3)+($ Reo $\times 2))$ (Figure 2A). Increased viral titers were also recovered from normal organs, albeit at least 3 logs lower than in tumor (Figure 2A). Highest levels of non-tumor-associated virus were recovered from the tail, perhaps through endothelial damage at injection sites (Figure 2A). Despite virus detection in nontumor tissues, no overt toxicity was observed in mice treated with $\left(\mathrm{VEGF}_{165} \times 3\right)+($ Reo $\times 2)$.

$V E G F$-enhanced virotherapy depends upon host immune components. Therapy associated with $\left(\operatorname{VEGF}_{165} \times 3\right)+($ Reo $\times 2)$ was lost in NK-, $\mathrm{CD}^{+}$-, and $\mathrm{CD}^{+}$-depleted mice (Figure $2 \mathrm{~B}$ ), showing that host immune cells are necessary for $V_{E G F} 165$-enhanced Reo therapy.
We characterized further the relative importance of $\mathrm{VEGF}_{165^{-}}$ mediated enhanced virus access to, and replication in, established tumors compared with host antiviral immune reactivity. Therefore, we tested $\left(\operatorname{VEGF}_{165} \times 3\right)+($ Reo $\times 2)$ against B16ova tumors, a B16 variant that supports very poor Reo replication (Figure $2 \mathrm{C}$ ) and cytotoxicity (not shown) in vitro. Even so, 3 weekly cycles of $\left(\right.$ VEGF $\left._{165} \times 3\right)+($ Reo $\times 2)$ were as successful against B16ova tumors (Figure 2C) as against B16 tumors (Figure 1B), indicating that viral activity against nontumor cells is critical.

In this respect, $\mathrm{B} 16$ in $\mathrm{C} 57 \mathrm{BL} / 6$ mice was consistently cured by 3 cycles of $\left(\operatorname{VEGF}_{165} \times 3\right)+($ Reo $\times 2)($ Figure $1 \mathrm{~B})$, but no therapeutic effect was seen in MyD88-deficient mice (Figure 2D). Significantly, although B16 tumors express MyD88 (data not 


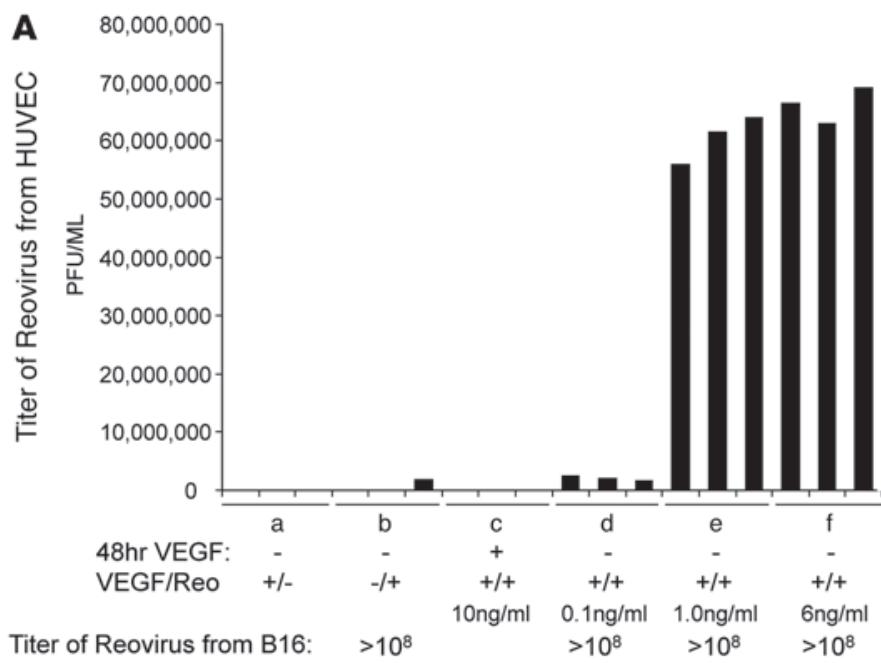

B

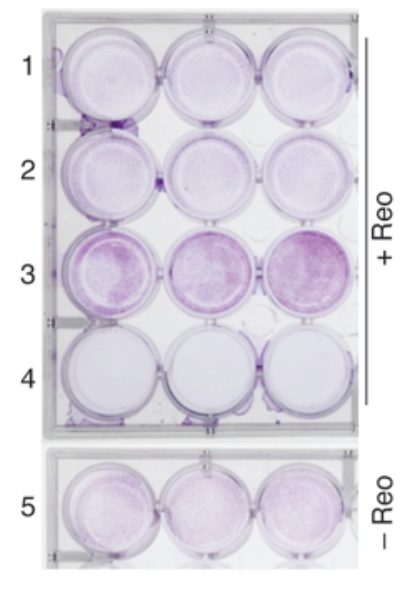

C

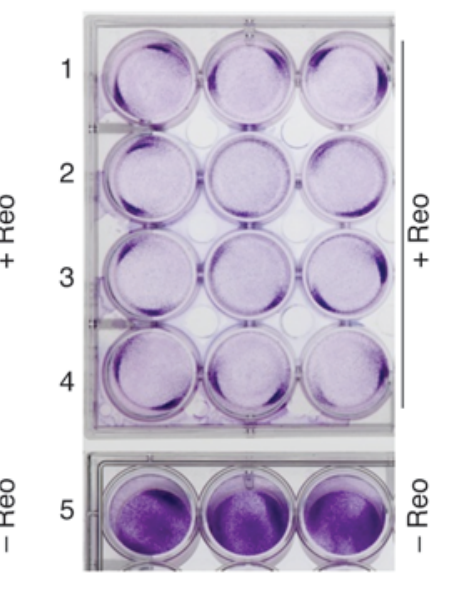

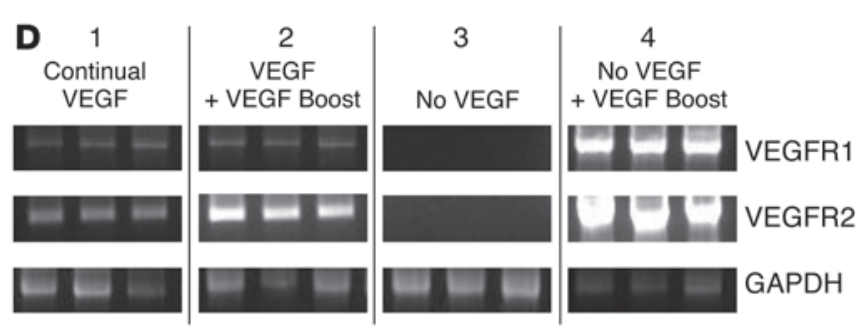

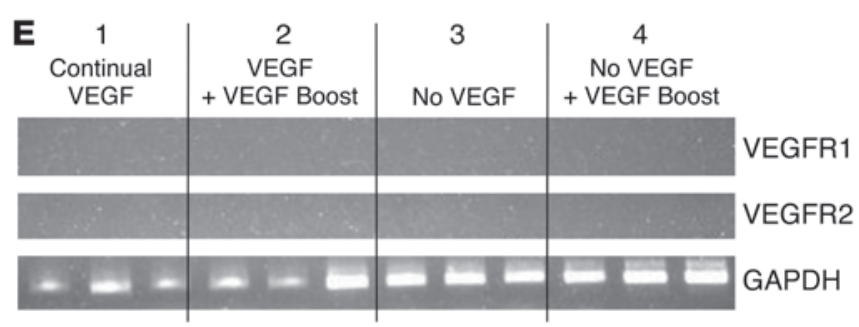

Figure 3

VEGF $_{165}$ burst conditions endothelial cells for Reo replication. (A) HUVEC or B16 tumor cells were cultured in triplicate wells in vitro for 48 hours in the absence of VEGF 165 (see groups a, b, and d-f) or continually with VEGF 165 present in the medium (group c) at $10 \mathrm{ng} / \mathrm{ml}$. Cultures were then exposed to mock infection (group a) or to Reo (MOl of 0.1) (groups b-f) in the presence of added VEGF 165 at $10 \mathrm{ng} / \mathrm{ml}(\mathrm{groups}$ a and c) or at $0.1 \mathrm{ng} / \mathrm{ml}$ (group d), $1.0 \mathrm{ng} / \mathrm{ml}$ (group e), or $6 \mathrm{ng} / \mathrm{ml}$ (group f). 72 hours later, viral titers were determined by plaque assay. (B and C) HUVEC (B) or B16 tumor cells (C) were cultured in triplicate wells in vitro for 48 hours continually with VEGF 165 present in the medium at $6 \mathrm{ng} / \mathrm{ml}$ (rows 1 , 2 , and 5) or in the absence of VEGF 165 (rows 3 and 4). Cultures were then exposed to mock infection (row 5) or to Reo (MOI of 0.1) (rows 1-4) in the presence of no VEGF 165 (row 3), $V_{E G F} 165$ at $12 \mathrm{ng} / \mathrm{ml}$ (row 2), or VEGF $\mathrm{VE}_{165}$ at $6 \mathrm{ng} / \mathrm{ml}$ (rows 1 and 4 ). 72 hours later, surviving cells were visualized by crystal violet staining. (D and E) RT-PCR analysis for expression of VEGFR1 and VEGFR2 genes in HUVEC (D) or B16 tumor cells (E) treated as described in treatments 1-4 in B and $\mathbf{C}$ above.

shown), the tumor-associated stroma, including host-derived endothelium, does not. Therefore, intact innate immune signaling through MyD88 nontumor cells is required for therapeutic efficacy of $3 \times\left(\operatorname{VEGF}_{165} \times 3\right)+($ Reo $\times 2)$.

To identify the host-derived compartment targeted by $\mathrm{VEGF}_{165^{-}}$ enhanced Reo activity, we examined the effects of therapy on tumor-associated endothelium. Consistent with our difficulty in evaluating vessel density in regressing B16 tumors in vivo (Figure 1, $C-G),\left(V_{E G F} 165 \times 3\right)+($ Reo $\times 2)$ markedly reduced mRNA for the endothelial-associated marker TIE2 (Figure 2E). In contrast, there was little change in expression of the tumor cell-associated marker gp100 at this stage (Figure 2E).

Taken together, the data in Figure 2 suggest that $\mathrm{VEGF}_{165} /$ Reo therapy may be mediated, at least initially, through viral-induced oncolysis and/or immune attack of $\mathrm{VEGF}_{165}$-activated endothelial cells rather than by direct viral replication/oncolysis in tumor cells.

$V E G F_{165}$ burst conditions endothelial cells for viral replication. Consistent with this hypothesis, HUVEC grown without VEGF ${ }_{165}$ supported Reo replication when VEGF $_{165}$ was reintroduced at suprathreshold levels, an effect that was absent in B16 cells (Figure 3A). $V_{E G F}{ }_{165}$-mediated conditioning of HUVEC for Reo replication was only induced in cells that had previously been deprived of $V E_{165}$. Boosting preexisting VEGF 165 levels (from $6 \mathrm{ng} / \mathrm{ml}$ to $12 \mathrm{ng} / \mathrm{ml})$ or sustained exposure yielded either low $\left(\sim 3 \times 10^{3}\right.$ median tissue culture infective dose $\left[\mathrm{TCID}_{50}\right]$ ) (data not shown) or no Reo replication in HUVEC (Figure 3A). HUVEC initially grown without $\mathrm{VEGF}_{165}$ and then pulsed with $\mathrm{VEGF}_{165}$ were extensively lysed by Reo (Figure 3B). As before, Reo cytotoxicity against B16 was unaffected by the presence/absence of $V_{E G F} 165$ (Figure 3C).

HUVEC grown continuously in $\mathrm{VEGF}_{165}$ maintained low, but detectable VEGFR1/2 expression (Figure 3D). Boosting preexisting VEGF $_{165}$ levels in vitro gave variable results over several experiments. In some, there was no detectable increase in VEGFR1/2 expression; in others, we observed an increase in VEGFR2 (Figure 3D). HUVEC grown without $\mathrm{VEGF}_{165}$ for 72 hours consistently downregulated VEGFR1/2 expression (Figure 3D). HUVEC grown for 48 hours without $\mathrm{VEGF}_{165}$, followed by de novo $\mathrm{VEGF}_{165}$ exposure, significantly induced VEGFR1/2, mirroring the increased reoviral replication under similar conditions (Figure 3A). B16 cells expressed neither VEGFR1 nor VEGFR2 irrespective of VEGF 165 exposure (Figure 3E).

Taken together, these data show that endothelial cells pulsed with VEGF $_{165}$ become permissive for reoviral replication and oncolysis. 
A

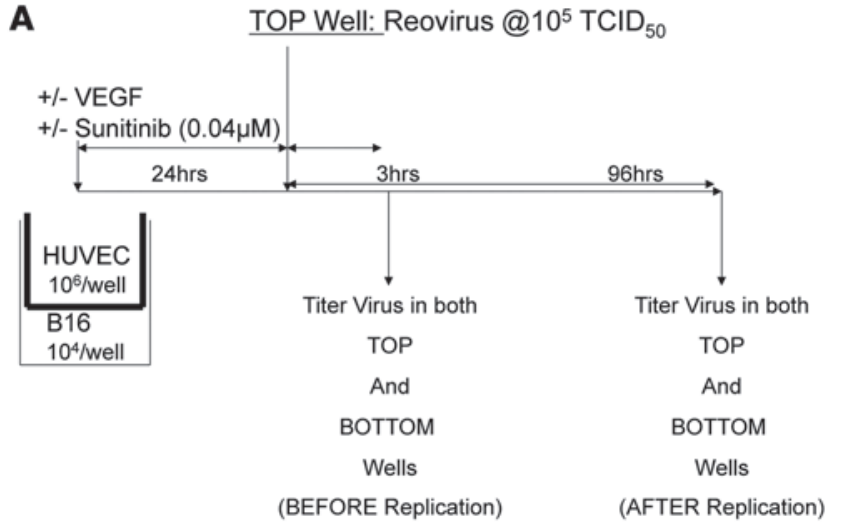

D
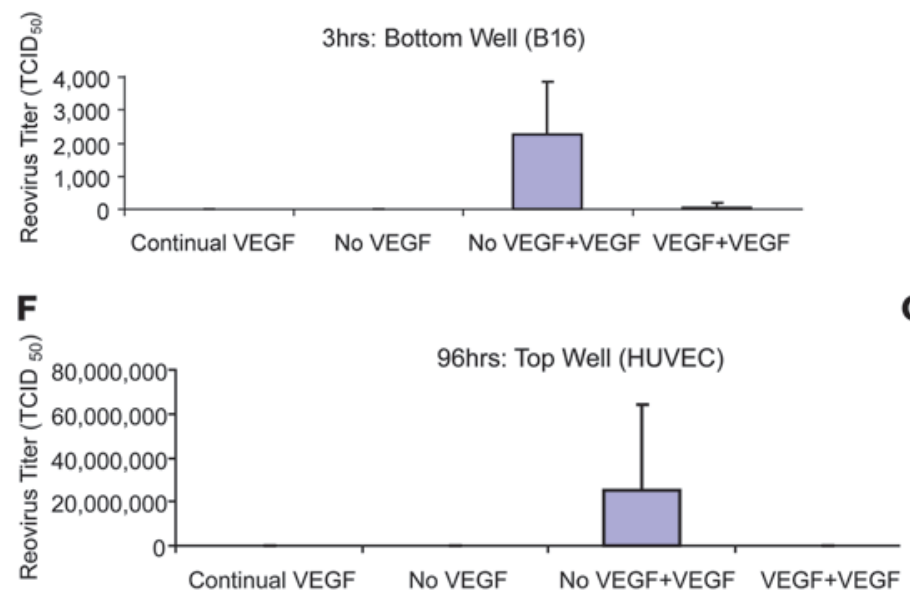

H

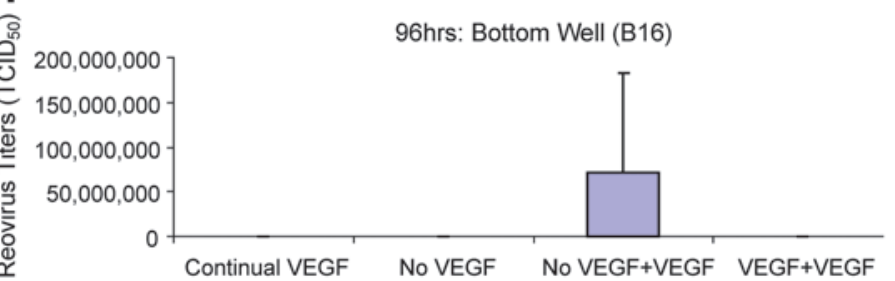

B
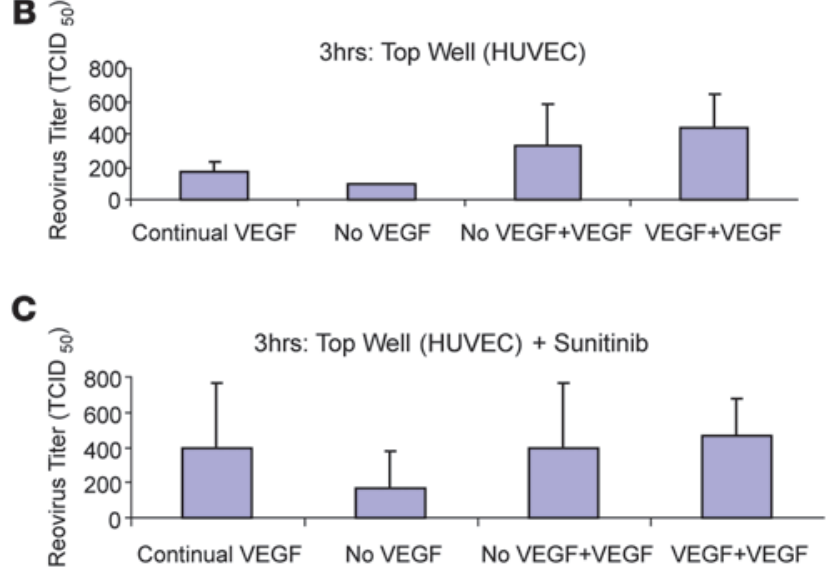

$\mathbf{E}$

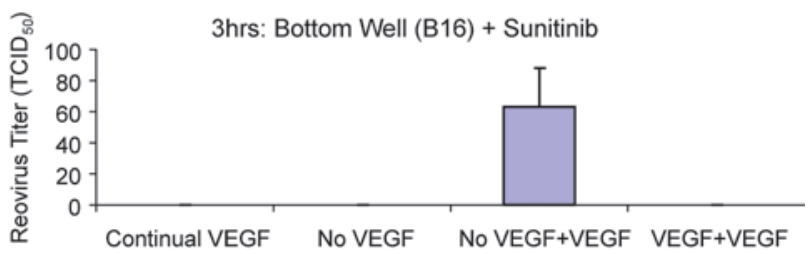

G

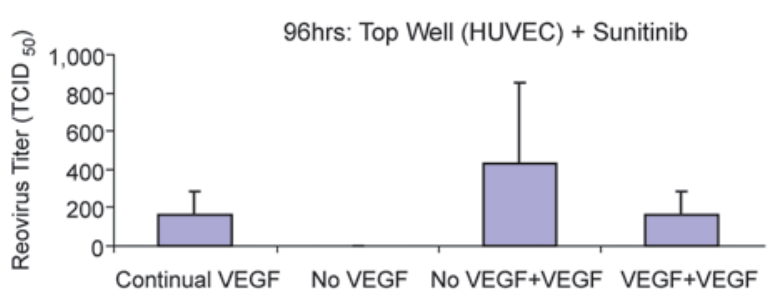

I

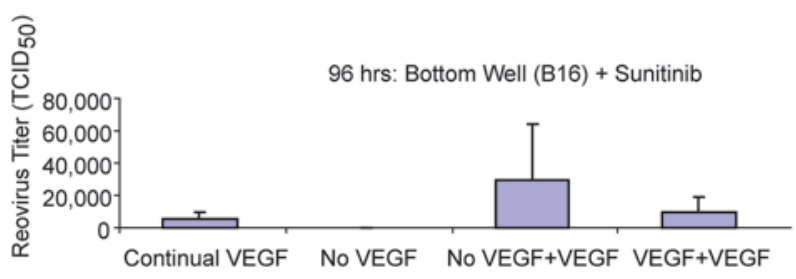

Figure 4

Transwell model of tumors separated from virus by an endothelial cell layer. (A) In vitro Transwell model to assess the effects on availability of Reo to B16 tumor cells separated from the virus source by a monolayer of HUVEC. (B-E) Transwells were set up in triplicate as shown in A. Triplicate Transwells were cultured for 48 hours continually with VEGF 165 present in the medium at $6 \mathrm{ng} / \mathrm{ml}$ or in the absence of VEGF 165 . All cultures were then exposed to Reo ( $\mathrm{MOI}$ of 0.1 ) either in the presence of VEGF 165 at $6 \mathrm{ng} / \mathrm{ml}, V_{E G F} \mathrm{~V}_{165}$ at $12 \mathrm{ng} / \mathrm{ml}$, or no VEGF 165 . One set of Transwells was also incubated with sunitinib as an inhibitor (C and $\mathbf{E})$. 3 hours after addition of VEGF ${ }_{165} /$ Reo to the top chamber, cells and supernatants from the top chambers (HUVEC; $\mathbf{B}$ and $\mathbf{C}$ ) or bottom chambers (B16; $\mathbf{D}$ and $\mathbf{E})$ were harvested and titered for Reo by plaque assay. (F-I) The

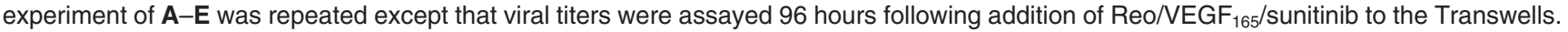

Importantly, conditioning was optimal when endothelial cells were first deprived of and then reexposed to a VEGF 165 burst.

Inhibition of VEGF 165 signaling abolishes conditioning for Reo replication. To investigate the mechanisms by which $\mathrm{VEGF}_{165}$ conditioning influences these effects on endothelial cells, we established an in vitro Transwell model with tumor cells separated from exposure to Reo by endothelial monolayers (Figure 4A). Within 3 hours of adding Reo to the endothelial cell-containing chamber, input virus was hardly detectable irrespective of the presence/absence of $\mathrm{VEGF}_{165}$ (Figure 4B) or sunitinib (a VEGFR inhibitor) (Figure $4 C$ ), an effect which may be due to either rapid viral adhesion to or sequestration within the endothelial cells. When the endothelial layer was grown in continuous or no $\mathrm{VEGF}_{165}$, no virus reached the lower, tumor cell-containing chamber (Figure 4D). However, when the endothelial layer was first deprived of $\mathrm{VEGF}_{165}$, followed by 24 hours reexposure, it became permeable to virus (Figure 4D), an effect that was abrogated by sunitinib $(P<0.01$ with respect to no sunitinib) (Figure 4E). 
A

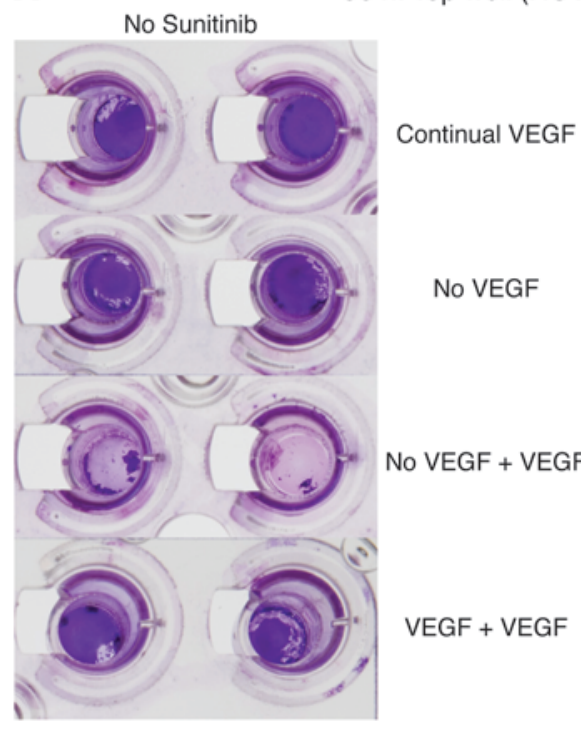

B

$96 \mathrm{~h}$ : Bottom well (B16)

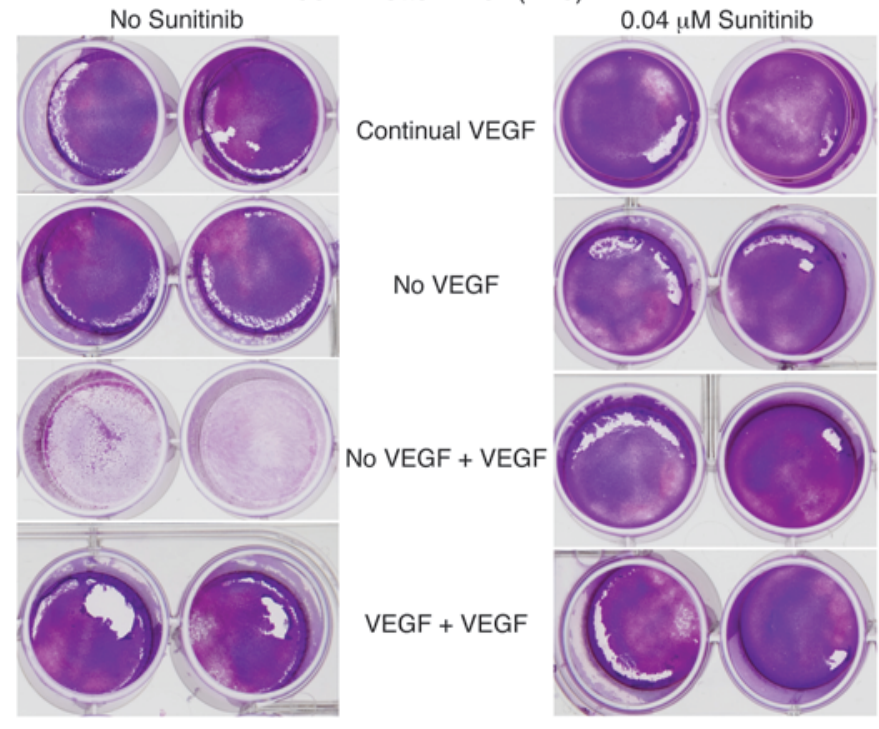

\section{Figure 5}

Sunitinib inhibition of VEGF-induced Reo replication. (A and B) At the end of the 96-hour time point (Figure 4, F-I), cytotoxicity to both the HUVEC (upper chamber, A) and B16 tumor cells (lower chamber, B) were visualized by crystal violet staining.

ing a VEGF burst conditions them for efficient reoviral replication. We hypothesized that treating $\mathrm{VEGF}_{165}$-producing tumors with a VEGF inhibitor and then withdrawing treatment to allow the VEGF level to rebound might also condition endothelium for enhanced Reo replication. To test this hypothesis, we replaced VEGF $_{165}$-nonproducing B16 with $\mathrm{VEGF}_{165}$-expressing B16 cells (B16-VEGF) (39) in the experiments depicted in Figure 1. In one experiment, $\left(\mathrm{VEGF}_{165} \times 3\right)+($ Reo $\times 2)$ was no better than $(\mathrm{PBS} \times 3)+($ Reo $\times 2)(P>0.05)$, and in another, $\left(\operatorname{VEGF}_{165} \times 3\right)+($ Reo $\times 2)$ prolonged survival $(P=0.05)$ but did not yield cures, in contrast to what is shown in Figure 1B. These data support our hypothesis that continual $\mathrm{VEGF}_{165}$ signaling to tumor-associated endothelium does not confer permissivity for Reo replication (Figures 3 and 4).

Using data from the Transwell model with HUVEC, sunitinib, and B16-VEGF cells (data not shown), we assessed various schedules of sunitinib and Reo. Sunitinib alone had no therapeutic effects on B16-VEGF tumors (Figure 6A) compared with PBS or Reo alone (data not shown). Separation of 2 daily doses of sunitinib from 2 daily doses of Reo by 48 hours significantly delayed growth of B16-VEGF tumors $(P<0.02$ vs. PBS or Reo alone), although most tumors showed only transient growth retardation (Figure 6B). In contrast, a 24-hour interval between finishing sunitinib and starting Reo was significantly more effective, leading to prolonged regression and a single cure (Figure 6C).

Thus, we developed an extended treatment schedule that cured B16-VEGF tumors using 3 cycles of (sunitinib $\times 3$ ) and i.v. $($ Reo $\times 2)$. Neither agent alone showed activity (Figure 6D). Therefore, treatment of VEGF-expressing tumors with a VEGFR inhibitor combined with i.v. Reo yields significant antitumor therapy.

Broad applicability of inbibition of VEGF $F_{165}$ signaling

Consistent with Figure 3, 72 hours after exposing endothelial cells that were deprived of and then pulsed with VEGF 165 to Reo, high titers were recovered from the upper chambers $(P<0.02$ compared with $\mathrm{VEGF}_{165}+$ additional $\mathrm{VEGF}_{165}$ ) (Figure 4F). Viral replication in the upper chamber was significantly $(P<0.001)$ inhibited by sunitinib (Figure 4G). Consistent with a model in which virus replicating in endothelium infects underlying tumor cells, viral replication in the lower chambers paralleled that in the upper chambers and was sunitinib sensitive (Figure 4, H and I). Viral production under the conditions in Figure 4, B-I, closely correlated with direct cytotoxicity to endothelial (Figure 5A) and underlying tumor cells (Figure 5B).

Taken together, these data show that $\mathrm{VEGF}_{165}$ burst to endothelial layers both allows increased viral passage across the endothelial layer and provides a source of replicating virus to infect underlying tumor cells.

Inbibitors of VEGF ${ }_{165}$ signaling can be combined with oncolytic virotherapy. Depriving endothelial cells of $\mathrm{VEGF}_{165}$ and then providwith oncolytic virotherapy. We have shown that manipulation of $V$ GFF $_{165}$ signaling in combination with systemic Reo is effective in 2 different melanoma tumor models that either express low (Figure 1B) or high (Figure 6D) levels of $\mathrm{VEGF}_{165}$ and in 1 variant tumor model that supports replication of the virus only very poorly (Figure 2C). We also demonstrated flexibility in the use of the inhibitor of $\mathrm{VEGF}_{165}$ signaling. Thus, although sunitinib showed no activity against B16-VEGF tumors (Figure 6D), Avastin/bevacizumab $(27,40)$ was therapeutic in this model (Figure 7A). Nonetheless, 2 doses of i.v. Reo within 4-6 and 24 hours of the last of 3 daily doses of Avastin was superior to Avastin $(P<0.01)$ or Reo alone $(P<0.001)$ (Figure $7 \mathrm{~A})$. Finally, combined VEGF inhibition and oncolytic virotherapy can be extended to another agent, VSV, to improve responses in B16-VEGF tumors $(P<0.02$ vs. sunitinib or VSV alone) (Figure $7 \mathrm{~B})$, although longterm cures were not seen with the schedule that was optimal for sunitinib/Reo (Figure 6D). 

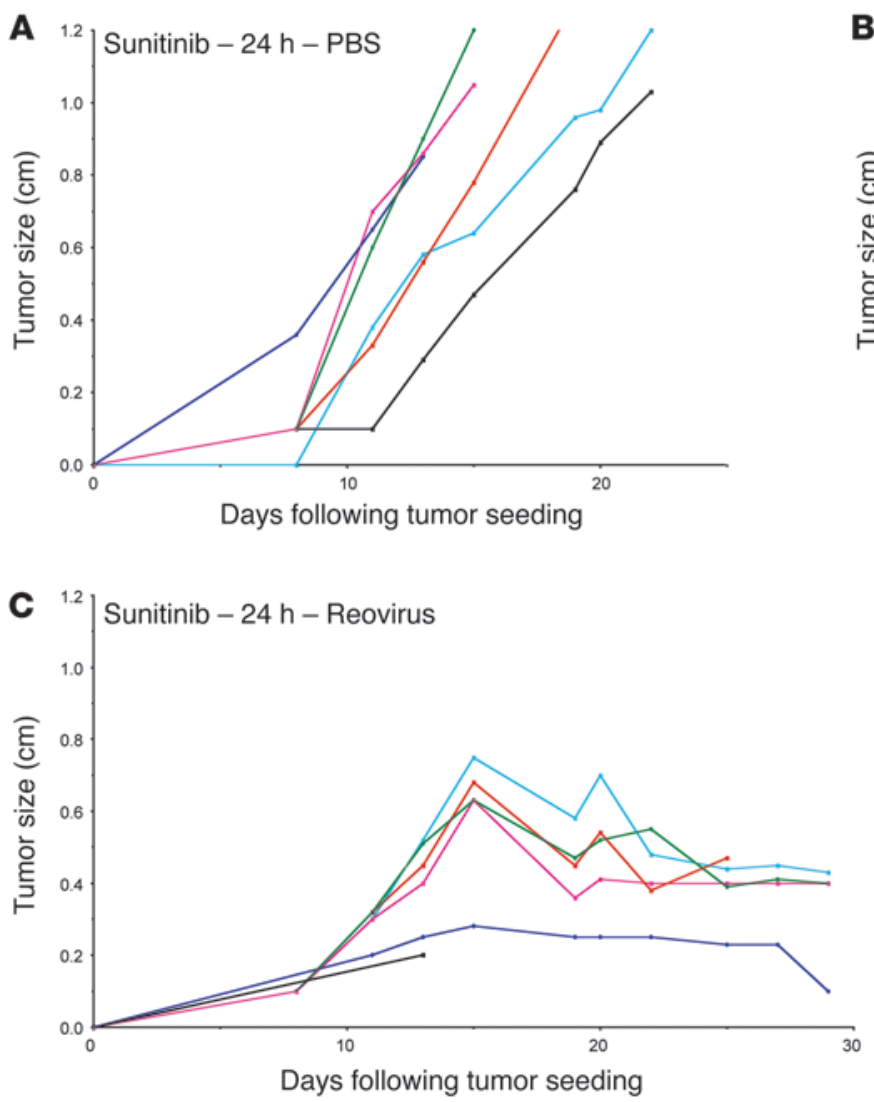

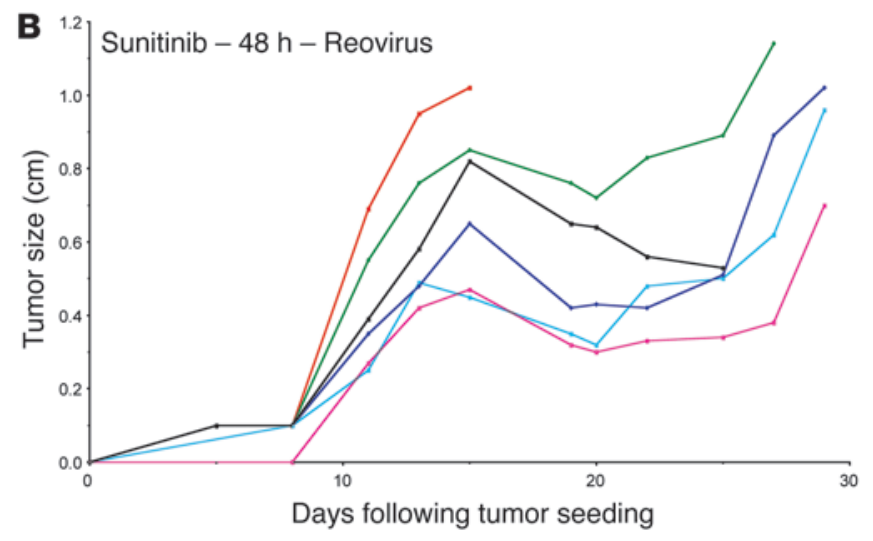

D

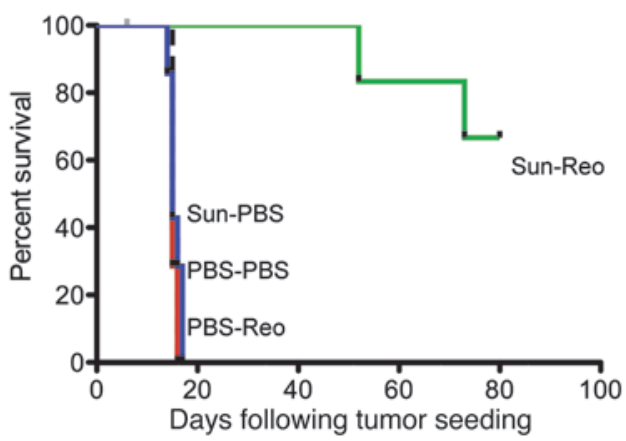

\section{Figure 6}

Sunitinib inhibition of VEGF 165 -producing tumors synergizes with systemic Reo. (A-C) C57BL/6 mice bearing subcutaneous B16-VEGF tumors established 7 days previously were treated (days 1-2) with a single injection per day for 2 consecutive days of sunitinib followed by a single i.v. injection per day for 2 consecutive days of either (A) PBS 24 hours following the last sunitinib injection (days 3, 4); (B) Reo 48 hours following the last sunitinib injection (days 4, 5); or (C) Reo 24 hours following the last sunitinib injection (days 3, 4). (D) C57BL/6 mice bearing B16-VEGF tumors established 7 days previously in C57BL/6 mice (7-8/group) were treated (days 1-3) with a single injection per day for 3 consecutive days of sunitinib or PBS followed 24 hours later (days 4,5 ) by a single i.v. injection per day for 2 consecutive days of Reo or PBS. This regimen was then repeated (days 8-12 and 15-19) twice in surviving mice. Survival was followed over time.

\section{Discussion}

Here we describe what we believe to be a novel method by which clinically approved inhibitors of $\mathrm{VEGF}_{165}$ can be combined with systemic delivery of oncolytic viruses, which should potentially be applicable to treating a broad range of cancers. We initially hypothesized that VEGF 165 would transiently destabilize and permeabilize tumor vasculature $(27,41)$ and enhance localization of circulating virus to establish spreading, therapeutic oncolytic infections. We determined a nontoxic VEGF $_{165}$ dosing schedule that did not promote tumor growth but induced vascular leak and systemic delivery of Reo to VEGF-nonexpressing B16 tumors (Figure 1A). Empirical expansion of this regimen involving multiple $\mathrm{VEGF}_{165}$ doses combined with systemic Reo $\left(3 \times\left[\left(\operatorname{VEGF}_{165} \times 3\right)+(\right.\right.$ Reo $\left.\left.\times 2)\right]\right)$ yielded long-term tumor cures (Figure $1 \mathrm{~B})$.

Consistent with this hypothesis, $\mathrm{VEGF}_{165} /$ Reo was associated with increased virus recovery from tumors (Figure 2A). Furthermore, $V_{E G F} 165$ treatment of endothelial layers enhanced the passage of virus across an endothelial layer in vitro (Figure 4D). However, other observations suggested that increased virus access is not the only mechanism mediating the success of $\left(3 \times\left[\left(\operatorname{VEGF}_{165} \times 3\right)+(\right.\right.$ Reo $\left.\left.\times 2)\right]\right)$.
Therapy depended on host-derived NK, $\mathrm{CD}^{+}$, and $\mathrm{CD}^{+} \mathrm{T}$ cells (Figure 2B) and host-derived MyD88-dependent innate signaling (Figure 2D). Although B16 tumors expressed MyD88 (data not shown), the MyD88-deficient tumor-associated stroma, including host-derived endothelial cells, did not. Therefore, intact innate MyD88 signaling in nontumor cells was required for therapy with $3 \times\left[\left(\operatorname{VEGF}_{165} \times 3\right)+(\right.$ Reo $\left.\times 2)\right]$ in immunocompetent mice. Tumor histology (Figure 1, C-G) indicated extensive destruction of intratumoral vessels, and we observed preferential loss of TIE2+ve endothelial cells, relative to gp100+ve tumor cells, at early stages following $\mathrm{VEGF}_{165}$-enhanced virus delivery (Figure $2 \mathrm{E}$ ). We also observed virus localization/replication in nontumor tissues that normally do not support Reo replication (Figure 2A), which presents a potential toxicity concern for the translation of these studies into clinical trials. Preliminary studies in our laboratory have suggested that the increased levels of virus in tumor, as opposed to other tissues, may be explained by a tumor-specific enhancement of endothelial toxicity associated with $\mathrm{VEGF}_{165}$ treatment and Reo replication. Thus, endothelial cells cocultured with tumor cells become significantly more susceptible to the $\mathrm{VEGF}_{165}$ burst-induced replication of Reo compared with endothelial cells cultured alone or 

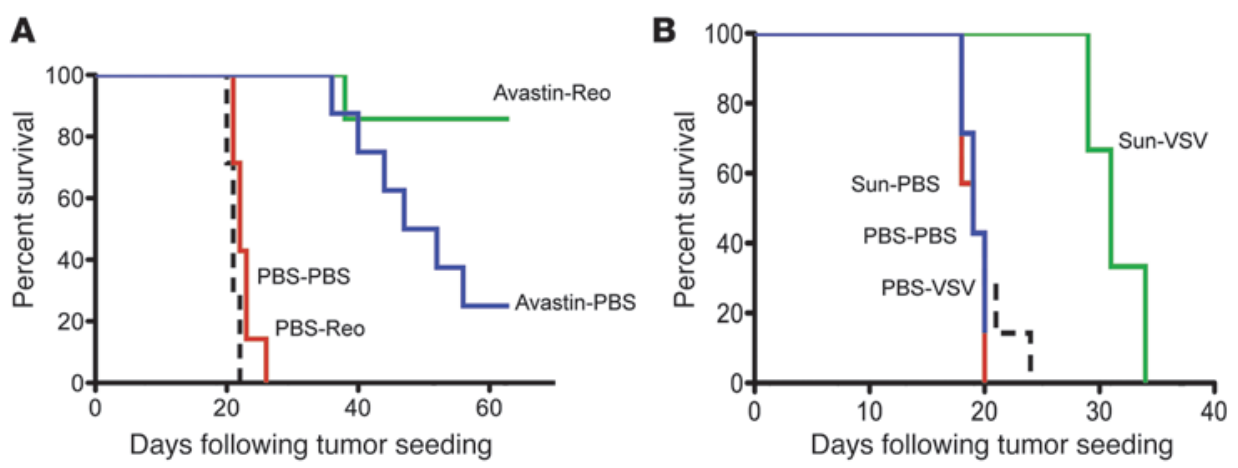

Figure 7

Treatment of VEGF 165 -producing tumors with VEGF inhibitor and systemic oncolytic virus. (A) C57BL/6 mice bearing B16-VEGF tumors established 7 days previously in C57BL/6 mice (7-8/group) were treated (days 1-3) with a single injection per day for 3 consecutive days of Avastin or PBS followed 6 and 30 hours later by i.v. injections of Reo or PBS. This regimen was then repeated twice in surviving mice. Survival was followed over time. (B) C57BL/6 mice bearing B16-VEGF tumors established 7 days previously in C57BL/6 mice (7-8/group) were treated (days 1-3) with a single injection per day for 3 consecutive days of sunitinib or PBS followed 24 hours later (days 4,5 ) by a single i.v. injection for 2 consecutive days of VSV $\left(5 \times 10^{8} \mathrm{PFU}\right)$ or PBS. This regimen was then repeated (days 8-12 and 15-19) twice in surviving mice. Survival was followed over time.

in the presence of nontransformed cells. These ongoing studies indicate that tumors secrete factors, which enhance the vascular collapse induced by VEGF 165 -induced Reo replication and immunemediated attack, compared with normal tissues. Such observations will help to explain, at least in part, the lack of systemic toxicity observed in treated mice, despite the increased appearance of virus in normal tissues upon $\mathrm{VEGF}_{165} /$ Reo treatment (Figure $2 \mathrm{~A}$ ). We believe that this may be explained by the inability of the virus to reach threshold levels of replication required for immune-mediated damage in normal organs, while exceeding those levels in tumors. Nonetheless, very close monitoring for toxicities associated with vascular damage to normal tissues will be required upon clinical translation of these studies. Finally, in vivo therapy did not correlate with the virus' ability to replicate in tumor cells (B16 vs. B16ova) in vitro (Figure 2C). Taken together, data from Figures 1 and 2 support the hypotheses that virus infection of endothelial cells may be an important source of intratumoral virus and that $\operatorname{VEGF}_{165} /$ Reo therapy also involves viral-induced immune attack

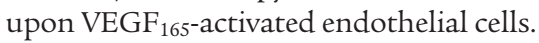

The observation that endothelial cells exposed to supra-threshold levels of $\mathrm{VEGF}_{165}$ support lytic reoviral replication supports these hypotheses (Figure 3, A and B). Conditioning of endothelial cells was optimal when $\operatorname{VEGF}_{165}$ was initially absent and then restored as a "VEGF 165 burst," coinciding with induction of VEGFR1/2 (Figure 3). The concentrations of VEGF 165 used in our in vitro studies are biologically relevant levels of $\mathrm{VEGF}_{165}$, at least as they relate to signaling through VEGF receptors. Significantly, we have not used abnormally high levels of $V \mathrm{VGF}_{165}$ in vitro to induce replication of virus in HUVEC. Instead, we have shown that it is the withdrawal of normal VEGF 165 signaling, followed by its reinstatement at normal levels, that is biologically important. It seems likely that $\mathrm{VEGF}_{165}$-VEGFR1/2 intracellular signaling establishes a "proviral" proliferative state within endothelial cells similar to that in Ras-activated tumor cells $(15,42-44)$ - consistent with data showing inhibition of $\operatorname{VEGF}_{165}$ conditioning by sunitinib-induced VEGFR blockade (Figure 4) (34-37). We are cur- rently investigating $\mathrm{VEGF}_{165}$ burstinduced signaling events in HUVEC and correlating these with signaling pathways exploited by Reo in tumor cells (21). Preliminary in vitro studies have confirmed that $\mathrm{VEGF}_{165^{-}}$ mediated signaling to HUVEC facilitates Reo replication specifically through VEGFR2 signaling (T. Kottke et al., unpublished observations), although sensitivity to NK activation following Reo infection may be mediated through alternative signaling pathways.

From these data, we propose a model in which mechanisms other than enhanced reoviral delivery through $\mathrm{VEGF}_{165}$-mediated vascular permeabilization contribute to the efficacy of $3 \times\left[\left(\right.\right.$ VEGF $\left._{165} \times 3\right)+$ $($ Reo $\times 2)]$ treatment. Thus, direct systemic infection and lysis of VEGF ${ }_{165}-$ activated tumor endothelium combine with innate immune-triggered destruction of virally infected endothelium to cause intratumoral vascular collapse. Although the relative importance of each mechanism to tumor regression is unclear, the strict dependence of therapy upon MyD88 signaling shows that innate antiviral immunity is critically important. Our data here are therefore highly consistent with the proposal that a major component of the efficacy associated with oncolytic virotherapy is contributed by the induction of vascular collapse, leading to profound bystander killing of the associated tumor cells, as described by Breitbach and colleagues (45).

Our Transwell assay (Figure 4), mimicking the in vivo situation of tumor cells underlying an endothelial layer, showed that a burst of $V_{E G F} 165$ signaling to endothelial cells supports virus replication, which feeds virus to underlying tumor cells. It may be that in vivo VEGF $_{165}$ burst renders the endothelium of multiple tissues/organs susceptible to Reo infection. However, the tumor cell specificity of released virus extinguishes replication and cytotoxicity in normal tissues and allows selective amplification within tumors (Figure 2A). This explains both the tolerability and efficacy of $3 \times\left(\operatorname{VEGF}_{165} \times 3\right)+($ Reo $\times 2)$, despite recovering virus from several nontumor sites. We are also currently investigating the possibility that tumor-associated endothelium is significantly more susceptible to $\mathrm{VEGF}_{165}$ enhanced Reo infection/replication than endothelial cells of nontumor tissues (Figure 2A).

Since deprivation and subsequent reinstatement of VEGF ${ }_{165}$ signaling to HUVEC cells promotes Reo replication (Figures 1-5), we hypothesized that treating a VEGF 165 -producing tumor with a VEGF 165 inhibitor and then withdrawing that treatment might similarly expose tumor-associated endothelial cells to a VEGF burst and license Reo replication. Therefore, sunitinib and i.v. Reo led to significant antitumor therapy in B16-VEGF tumors (Figure 6). The temporal sequence of VEGF $_{165}$ inhibitor and Reo was critical - consistent with a model in which recovery of suprathreshold VEGF ${ }_{165}$ signaling to tumor-associated endothelium mediates susceptibility to Reo infection/lysis. The levels of VEGF produced by our B16-VEGF tumors were not high enough consis- 
tently to elevate serum levels of VEGF, even in C57BL/ 6 mice bearing 15-day established tumors. This contrasts with the ability of patient tumors to produce high enough levels to be detectable in the serum. Therefore, we believe that the B16-VEGF clones used in the current study produce VEGF at comparable, if not lower, levels than many human tumors in patients.

Finally, we demonstrated the broad potential applicability of combining $\mathrm{VEGF}_{165}$ inhibition and oncolytic virotherapy. Variations on the approach of manipulating $\mathrm{VEGF}_{165}$ signaling to the endothelium in combination with systemic Reo were effective in 3 different melanoma models. In addition, we have recently shown

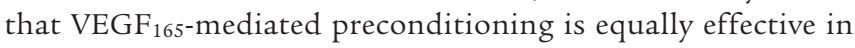
combination with systemic Reo in additional transplantable tumor models of different histological types, and experiments are underway to test the efficacy of the approach in transgenic models of spontaneous tumor development. With respect to the flexibility of using different antiangiogenic inhibitors, sunitinib was replaceable by Avastin in combination with i.v. Reo. Despite the reported long half-life of Avastin, viral administration was still required relatively quickly following the third injection. We hypothesize that very high local levels of $V_{E G F} F_{165}$ produced from the engineered B16-VEGF tumors create a rapid rebound of VEGF $_{165}$ signaling to tumor-associated endothelium even in the presence of long-lived, but subsaturating levels of Avastin molecules. More detailed pharmacological studies on the levels of both sunitinib and Avastin achieved within tumors are ongoing. In addition, sunitinib-mediated $V_{E G F}$ Fr $_{165}$ inhibition was therapeutic in B16-VEGF tumors when combined with a completely different oncolytic virus, namely VSV, although efficacy was less pronounced than for Reo. Overall, these data suggest that the combinational technology described here will both have broad applicability (multiple tumor types) and allow for flexibility regarding both the inhibitors of VEGF $_{165}$ signaling (e.g., Avastin or sunitinib) and the oncolytic virus that is used clinically.

Our results are clinically applicable in 2 distinct situations. First, in patients with $V_{E G F} F_{165}$-nonexpressing tumors, pulsed VEGF 165 treatment followed with i.v. oncolytic virus could be tested. However, very real concerns about potential tumor growth-promoting effects of pulsed VEGF 165 treatment would have to be addressed, especially if the patients' tumors were known to express VEGFR2. Second, in patients with VEGF-expressing tumors (e.g., renal cell, ovarian), VEGF 165 inhibitors (sunitinib, Avastin) could be administered and then withdrawn to induce a VEGF burst during which oncolytic virotherapy could be given (34-37). This scenario is most appealing for clinical translation.

In summary, we have shown that manipulating VEGF 165 signaling pathways within the tumor microenvironment enables systemic delivery of oncolytic virotherapy. Therapy is associated with increased vascular permeability to circulating virus, $V_{E G F}{ }_{165}$-mediated induction of viral replication in and lysis of endothelial cells, and innate immune-mediated attack on virally infected vasculature. Importantly, because this combinatorial approach targets the tumor endothelium, these data have direct, wide-ranging, and immediate clinical applicability across a broad range of tumor types using reagents that are already approved for use in patients.

\section{Methods}

Cells and viruses. B16 murine melanoma cells $\left(\mathrm{H} 2-\mathrm{K}^{\mathrm{b}}\right)$ have been described previously (46). B16ova (H-2Kb) (gift from Esteban Celis, Moffitt Cancer Center, University of South Florida, Tampa, Florida, USA) stably express the chicken ovalbumin gene (46). HUVEC were purchased from ATCC and cultured as directed. Cell lines were monitored routinely and were free of Mycoplasma infection.

WT Reo type 3 (Dearing strain) stock titers were measured by plaque assays on L929 cells. VSV was generated, plaque purified, concentrated, and plaque assayed as described in ref. 47. For in vivo studies, Reo and VSV were administered i.v. at $10^{8} \mathrm{TCID}_{50}$ and $5 \times 10^{8} \mathrm{PFU}$, respectively, per injection.

$V E G F_{165}$ and VEGF 165 inhibitors. Recombinant mouse VEGF 165 (ProSpec) was used in vivo at $1 \mu \mathrm{g}$ per injection. Sunitinib (LC Laboratories), a VEGFR tyrosine kinase inhibitor, was used at $0.04 \mu \mathrm{M}$ in vitro and in vivo at $8 \mathrm{mg}$ /i.p. injection (48). Avastin (bevacizumab) (Mayo Cytotoxic Pharmacy) was used in vivo at $30 \mu \mathrm{g} /$ injection (40).

In vivo studies. Procedures were approved by the Mayo Foundation Institutional Animal Care and Use Committee. C57BL/6 mice (6-8 weeks old) (Jackson Laboratories) were injected subcutaneously with $2 \times 10^{5} \mathrm{~B} 16$ or B16ova cells (100 $\mu$ l PBS). Bidimensional tumor diameters were measured thrice weekly using calipers, and mice were killed when actively progressing tumors exceeded $1.0 \times 1.0 \mathrm{~cm}$. Immune cell depletions involved i.p. injections $(0.1 \mathrm{mg} / \mathrm{mouse}$ ) of anti-CD8 (Lyt 2.43), anti-CD4 (GK1.5) (Monoclonal Antibody Core Facility; Mayo Clinic), and IgG control (ChromPure Rat IgG; Jackson ImmunoResearch). For NK depletion, approximately $0.75 \mathrm{mg} / \mathrm{mouse}$ anti-asialo-GM1 (Cedarlane) or rabbit IgG isotype control (Jackson ImmunoResearch Laboratories) was injected i.p. FACS of spleens and/or lymph nodes confirmed subset-specific depletions.

Virus titration from tumor and organs. Tumor/organs were harvested from mice, weighed, and lysed ( 3 freeze-thaw cycles within 2 hours of removal). Virus in lysates was titered on $\mathrm{L} 929$ cells and expressed as $\mathrm{TCID}_{50} / \mathrm{mg}$ tissue.

RT-PCR. $1 \mu \mathrm{g}$ total RNA from cells/tumors (QIAGEN RNA Extraction Kit) was reverse transcribed using oligo(dT) primer. cDNA equivalent of 1 ng RNA was amplified for murine TIE2 (TIE2 PCR primer pair, no. RDP-50; R\&D Systems), human VEGFR1/2 using primers described in ref. 49, and gp100 using the following primers: (forward) 5 -ACATTTCATCACCAGGGTGCC-3'; (reverse) 5'-CAGGAACAAGTTGGGTGCT-3'.

Histopathology of tumor sections. Tumors were harvested, fixed in $10 \%$ formalin, paraffin-embedded, and sectioned. Two independent pathologists examined H\&E sections, blinded to the experimental design.

Statistics. Survival data from the animal studies was analyzed by log-rank test (50). Two-sample unequal variance Student's $t$ test analysis was applied for in vitro assays. Statistical significance was determined at $P<0.05$.

\section{Acknowledgments}

We thank Toni Higgins for expert secretarial assistance. This work was supported by the Richard Schulze Family Foundation, the Mayo Foundation, and by NIH grants CA107082, CA132734, and CA130878.

Received for publication October 14, 2009, and accepted in revised form January 27, 2010.

Address correspondence to: Richard Vile, Mayo Clinic, Gugg 18, 200 First Street SW, Rochester, Minnesota 55905, USA. Phone: 507.284.3178; Fax: 507.266.2122; E-mail: vile.richard@mayo.edu.
1. Fisher K. Striking out at disseminated metastases: the systemic delivery of oncolytic viruses. Curr Opin Mol Ther. 2006;8(4):301-313.

2. Harrington K, Vile R. Virus smuggling, tax evasion and tumor assassination. Nat Med. 2006;12(5):507-509.

3. Qiao J, et al. Cyclophosphamide facilitates anti tumor efficacy against subcutaneous tumors fol- lowing intravenous delivery of Reovirus. Clin Cancer Res. 2008;14(1):259-269.

4. Fulci $\mathrm{G}$, et al. Cyclophosphamide enhances glioma virotherapy by inhibiting innate immune responses. 
Proc Natl Acad Sci US A. 2006;103(34):12873-12878

5. Harrington $\mathrm{K}$, et al. Cells as vehicles for cancer gene therapy: the missing link between targeted vectors and systemic delivery? Hum Gene Ther. 2002;13(11):1263-1280.

6. Kottke T, et al. Use of biological therapy to enhance both virotherapy and adoptive T-cell therapy for cancer. Mol Ther. 2008;16(12):1910-1918.

7. Qiao J, et al. Purging metastases in lymphoid organs using a combination of antigen-nonspecific adoptive $T$ cell therapy, oncolytic virotherapy and immunotherapy. Nat Med. 2008;14(1):37-44.

8. Power AT, Bell JC. Cell-based delivery of oncolytic viruses: a new strategic alliance for a biological strike against cancer. Mol Ther. 2007;15(4):660-665.

9. Thorne SH, Negrin RS, Contag CH. Synergistic antitumor effects of immune cell-viral biotherapy. Science. 2006;311(5768):1780-1784.

10. Hecht JR, et al. A phase I/II trial of intratumoral endoscopic ultrasound injection of ONYX-015 with intravenous gemcitabine in unresectable pancreatic carcinoma. Clin Cancer Res. 2003;9(2):555-561.

11. Kirn D, Martuza RL, Zwiebel J. Replication-selective virotherapy for cancer: Biological principles, risk management and future directions. Nat Med. 2001;7(7):781-787.

12. Liu TC, Kirn D. Gene therapy progress and prospects cancer: oncolytic viruses. Gene Ther. 2008;15(12):877-884

13. Cattaneo R, Miest T, Shashkova EV, Barry MA Reprogrammed viruses as cancer therapeutics: targeted, armed and shielded. Nat Rev Microbiol. 2008;6(7):529-540.

14. Guo ZS, Thorne SH, Bartlett DL. Oncolytic virotherapy: molecular targets in tumor-selective replication and carrier cell-mediated delivery of oncolytic viruses. Biochim Biophys Acta. 2008;1785(2):217-231.

15. Coffey MC, Strong JE, Forsyth PA, Lee PW. Reovirus therapy of tumors with activated Ras pathway. Science. 1998;282(5392):1332-1334

16. Wilcox ME, et al. Reovirus as an oncolytic agent against experimental human malignant gliomas. I Natl Cancer Inst. 2001;93(12):903-912.

17. Hirasawa $\mathrm{K}$, et al. Oncolytic reovirus against ovarian and colon cancer. Cancer Res. 2002;62(6):1696-1701.

18. Norman KL, et al. Reovirus oncolysis of human breast cancer. Hum Gene Ther. 2002;13(5):641-652.

19. Hirasawa K, et al. Systemic reovirus therapy of metastatic cancer in immune-competent mice. Cancer Res. 2003;63(2):348-353.

20. Thirukkumaran C, Morris DG. Oncolytic viral therapy using reovirus. Methods Mol Biol.
2009;542:607-634.

21. Comins C, Heinemann L, Harrington K, Melcher A, De Bono J, Pandha H. Reovirus: viral therapy for cancer 'as nature intended'. Clin Oncol ( $R$ Coll Radiol). 2008;20(7):548-554

22. Vidal L, et al. A phase I study of intravenous oncolytic reovirus type 3 Dearing in patients with advanced cancer. Clin Cancer Res. 2008;14(21):7127-7137.

23. White CL, et al. Characterization of the adaptive and innate immune response to intravenous oncolytic reovirus (Dearing type 3) during a phase I clinical trial. Gene Ther. 2008;15(12):911-920.

24. Liu TC, Kirn D. Systemic efficacy with oncolytic virus therapeutics: clinical proof-of-concept and future directions. Cancer Res. 2007;67(2):429-432.

25. Harrington KJ, Melcher A, Vassaux G, Pandha HS, Vile RG. Exploiting synergies between radiation and oncolytic viruses. Curr Opin Mol Ther. 2008;10(4):362-370.

26. Kumar S, Gao L, Yeagy B, Reid T. Virus combinations and chemotherapy for the treatment of human cancers. Curr Opin Mol Ther. 2008;10(4):371-379.

27. Ellis LM, Hicklin DJ. VEGF-targeted therapy: mechanisms of anti-tumour activity. Nat Rev Can cer. 2008;8(8):579-591.

28. Pilat MJ, Lorusso PM. Vascular disrupting agents. J Cell Biochem. 2006;99(4):1021-1039.

29. Thorpe PE. Vascular targeting agents as cancer therapeutics. Clin Cancer Res. 2004;10(2):415-427.

30. Tozer GM, Kanthou C, Baguley BC. Disrupting tumour blood vessels. Nat Rev Cancer. 2005;5(6):423-435.

31. Dvorak HF. Vascular permeability factor/vascular endothelial growth factor: a critical cytokine in tumor angiogenesis and a potential target for diagnosis and therapy. J Clin Oncol. 2002;20(21):4368-4380.

32. Hicklin DJ, Ellis LM. Role of the vascular endothelial growth factor pathway in tumor growth and angiogenesis. J Clin Oncol. 2005;23(5):1011-1027.

33. Kowanetz M, Ferrara N. Vascular endothelial growth factor signaling pathways: therapeutic perspective. Clin Cancer Res. 2006;12(17):5018-5022.

34. Casanovas O, Hicklin DJ, Bergers G, Hanahan D. Drug resistance by evasion of antiangiogenic targeting of VEGF signaling in late-stage pancreatic islet tumors. Cancer Cell. 2005;8(4):299-309.

35. Chow LQ, Eckhardt SG. Sunitinib: from rational design to clinical efficacy. J Clin Oncol. 2007;25(19):2858-2859.

36. Faivre S, Demetri G, Sargent W, Raymond E. Molecular basis for sunitinib efficacy and future clinical development. Nat Rev Drug Discov.
2007;6(9):734-745

37. Kane RC, et al. Sorafenib for the treatment of advanced renal cell carcinoma. Clin Cancer Res. 2006;12(24):7271-7278.

38. Jain RK. Normalization of tumor vasculature: an emerging concept in antiangiogenic therapy. Science. 2005;307(5706):58-62.

39. Jevremovic D, et al. Use of blood outgrowth endothelial cells as virus-producing vectors for gene delivery to tumors. Am J Physiol Heart Circ Physiol. 2004;287(2):H494-H500.

40. Li Q, et al. The therapeutic efficacy of anti vascular endothelial growth factor antibody, bevacizumab, and pemetrexed against orthotopically implanted human pleural mesothelioma cells in severe combined immunodeficient mice. Clin Cancer Res. 2007;13(19):5918-5925.

41. Gregorevic P, et al. Systemic delivery of genes to striated muscles using adeno-associated viral vectors. Nat Med. 2004;10(8):828-834.

42. Strong JE, Coffey MC, Tang D, Sabinin P, Lee PW. The molecular basis of viral oncolysis: usurpation of the Ras signaling pathway by reovirus. $E M B O J$. 1998;17(12):3351-3362.

43. Strong JE, Lee PW. The v-erbB oncogene confers enhanced cellular susceptibility to reovirus infection. J Virol. 1996;70(1):612-616.

44. Norman KL, Lee PWK. Not all viruses are bad guys: the case for reovirus in cancer therapy. Drug Discov Today. 2005;10(12):847-856.

45. Breitbach CJ, et al. Targeted inflammation during oncolytic virus therapy severely compromises tumor blood flow. Mol Ther. 2007;15(9):1686-1693.

46. Linardakis E, et al. Enhancing the efficacy of a weak allogeneic melanoma vaccine by viral fusogenic membrane glycoprotein-mediated tumor cell-tumor cell fusion. Cancer Res. 2002;62(19):5495-5504.

47. Fernandez M, Porosnicu M, Markovic D, Barber GN. Genetically engineered vesicular stomatitis virus in gene therapy: Application for treatment of malignant disease.J Virol. 2002;76(2):895-904.

48. Mendel DB, et al. In vivo antitumor activity of SU11248, a novel tyrosine kinase inhibitor targeting vascular endothelial growth factor and plateletderived growth factor receptors: determination of a pharmacokinetic/pharmacodynamic relationship. Clin Cancer Res. 2003;9(1):327-337.

49. El-Obeid A, et al. Immature B cell malignancies synthesize VEGF, VEGFR-1 (Flt-1) and VEGFR-2 (KDR). Leuk Res. 2004;28(2):133-137.

50. Altman DG. Analysis of survival times. In: Practical Statistics for Medical Research. London, UK: Chapman \& Hall; 1991:365-395. 